\title{
Spectral investigation of the Piperazine Dithiosemicarbazone Derivatives as inhibitor on High Carbon Steel in HCl media
}

\author{
R. Tamilarasan ${ }^{1}$, A. Sreekanth ${ }^{1^{*}}$ \\ 1. Chemistry Department, National Institute of Technology Tiruchirappalli, Tiruchirappalli620015 India.
}

Received 27Jan 2017,
Revised 04 Aug 2017,
Accepted 10 Aug 2017
Keywords
$\checkmark$ dithiosemicarbazone;
$\checkmark$ high carbon steel;
$\checkmark$ corrosion inhibition;
$\checkmark$ electrochemical studies;
$\checkmark$ FT-IR, XPS
$\quad$ Dr. A. Sreekanth
$\quad$ sreekanth@nitt.edu
$\quad+919489551851$

\section{Abstract}

The inhibition efficiency of the piperazine dithiosemicarbazone derivatives on the corrosion of high carbon steel in HCL medium were studied by electrochemical impedance spectroscopy (EIS), polarization (Tafel), X-ray Photoelectron Spectroscopy (XPS) and UV-Visible spectroscopy. Electrochemical studies show that piperazine based dithiosemicarbazone derivatives acts as mixed type of inhibitors on high carbon steel. XPS data revealed that the inhibitors are adsorbed on the high carbon steel surface. It's also obeying the Langmuir's adsorption isotherm.

\section{Introduction}

Corrosion inhibitors were a classical way of protecting the materials against deterioration due to corrosion, especially in corrosive acidic media [1]. Organic compounds containing heteroatoms like $\mathrm{O}, \mathrm{N}$, and $\mathrm{S}$ are known to have superior inhibition qualities [2, 3]. In comparison to the large plethora of the organic inhibitors available, thiosemicarbazone derivatives have been reportedly more effective in acid medium corrosion due to the presence of the $-\mathrm{C}=\mathrm{N}$ and $-\mathrm{C}=\mathrm{S}$ groups in the molecule. Azomethane group have been widely reported as excellent inhibition of mild steel corrosion in theacidic medium due to the $\pi$ electron donating ability. The nucleophilicity of the inhibitors evoked by $\pi$ or lone pair of anelectron on hetero atoms while binding with the electrophilic metal surface. Thiosemicarbazone has been investigated by several authors as effective corrosion inhibitors for mild steel. Several N- heterocyclic derivatives have been established to be a corrosion inhibitor in acidic medium. Thiosemicarbazone generally become effective by adsorption on the metal surface. The adsorbed species, protect the metal from aggressive medium, which causes decomposition of the metal. Adsorption not only the nature and charge of the metal, but on the chemical structure of the inhibitor [4-6, 4647].

The aim of the present study to investigate the inhibiting properties of the Bis (pyridine-2-carboxaldehyde) piperazine dithiosemicarbazone $(\mathrm{C} 1)$ and Bis (Benzoylpyridine) piperazine dithiosemicarbazone $(\mathrm{C} 2)$ in the acidic medium. Mostly thiosemicarbazone derivative has been reported as protective in acidic medium, dithiosemicarbazone have a two $-\mathrm{C}=\mathrm{N}$ and $-\mathrm{C}=\mathrm{S}$ groups in the molecule and binding ability with steel more to reduce the corrosion. The inhibition efficiency of the inhibitor on the high carbon steel in $1 \mathrm{M} \mathrm{HCl}$ was studied by means Electrochemical impedance spectroscopy, Tafel curve X-ray photoelectron, UV-Visible and Infra-Red spectroscopy and adsorption isotherm parameters are discussed.

\section{Experimental details}

2.1. Preparation of Bis(pyridine-2-carboxaldehyde) piperazine dithiosemicarbazone $(\mathrm{Cl})$

$1 \mathrm{mmol}$ of piperazine dithiosemicarbazone was dissolved in $20 \mathrm{ml}$ of ethanol and $2 \mathrm{mmol}$ of the pyridine 2carbaldehyde was added to the solution and refluxed for 4 hours. A Yellow colored precipitate formed was then filtered, washed with ethanol and ether dried in a vacuum. Soluble in DMSO(Pale yellow) Yield: $85 \%$, M.P. 
$185^{0}$ C, Anal. Calc. for $\mathrm{C}_{13} \mathrm{H}_{14} \mathrm{~N}_{4} \mathrm{O}_{2} \mathrm{~S}_{1}: \mathrm{C}, 52.41 ; \mathrm{H}, 4.89 ; \mathrm{N}, 27.16 ; \mathrm{S}, 15.55$. Found: $\mathrm{C}, 52.38 ; \mathrm{H}, 5.82 ; \mathrm{N}$, 27.90; S, $15.53 \%$. IR data $\left(\mathrm{KBr}, \mathrm{cm}^{-1}\right) 3441(\mathrm{~N}-\mathrm{H}), 1572(\mathrm{C}=\mathrm{N}), 1294(\mathrm{C}=\mathrm{S}) .{ }^{1} \mathrm{H}-\mathrm{NMR}(500 \mathrm{MHz}$ DMSO-D 6 ppm) $4.3\left(8 \mathrm{H}, \mathrm{s}, \mathrm{CH}_{2}\right), 6.50(2 \mathrm{H}, \mathrm{t}, \mathrm{Ar}), 6.57(2 \mathrm{H}, \mathrm{d}, \mathrm{Ar}), 7.69(2 \mathrm{H}, \mathrm{d}, \mathrm{Ar}), 8.69(2 \mathrm{H}, \mathrm{d}, \mathrm{Ar}), 12.1(1 \mathrm{H}, \mathrm{s}, \mathrm{NH})$.

${ }^{13} \mathrm{C}-\mathrm{NMR}\left(125 \mathrm{MHz}, \mathrm{DMSO}_{6}\right.$, ppm):174.35 (1C, C=S), $166.35(1 \mathrm{C}, \mathrm{C}=\mathrm{N}), 151.11,112.00,111.94,111.10$ (4C, $\mathrm{Ar}), 44.33\left(1 \mathrm{C}, \mathrm{CH}_{2}\right)$.

\subsection{Synthesis of Bis (Benzoyl pyridine) piperazinedithiosemicarbazone $(C 2)$}

$1 \mathrm{mmol}$ of piperazine dithiosemicarbazone was dissolved in $20 \mathrm{ml}$ of ethanol and $2 \mathrm{mmol}$ of the Benzoyl pyridine was added to the solution and refluxed for 4 hours. A Yellow precipitate formed was then filtered and washed with ethanol and ether dried in a vacuum. Soluble in DMSO(Pale yellow) Yield: $88 \%$, M.P. $194^{0}$ C, Anal. Calc. for $\mathrm{C}_{30} \mathrm{H}_{28} \mathrm{~N}_{8} \mathrm{~S}_{2}$ : C, 63.80; H, 5.00; N, 19.84; S, 11.36. Found: C, 63.43; H, 4.91; N, 19.50; S, 11.23 \%. IR data $\left(\mathrm{KBr}, \mathrm{cm}^{-1}\right) 3441(\mathrm{~N}-\mathrm{H}), 1572(\mathrm{C}=\mathrm{N}), 1294(\mathrm{C}=\mathrm{S}) .{ }^{1} \mathrm{H}-\mathrm{NMR}(500 \mathrm{MHz}$ DMSO-D 6 ppm) $3.35(8 \mathrm{H}$, s, $\left.\mathrm{CH}_{2}\right), 6.50-7.42(\mathrm{Ar}), 12.30(1 \mathrm{H}, \mathrm{s}, \mathrm{NH}) .{ }^{13} \mathrm{C}-\mathrm{NMR}\left(125 \mathrm{MHz}, \mathrm{DMSO}-\mathrm{D}_{6, \mathrm{ppm}}\right): 182.58$ (1C, $\left.\mathrm{C}=\mathrm{S}\right), 160.35$ $(1 \mathrm{C}, \mathrm{C}=\mathrm{N}), 124.27-149.90,(\mathrm{Ar}), 46.76\left(1 \mathrm{C}, \mathrm{CH}_{2}\right)$

\subsection{Characterization of $C 1$ and $C 2$}

\subsubsection{Spectroscopic methods}

The UV-Visibleabsorption spectrum was measured in the SHIMADZU-UV-2101PC UV-Visible spectrophotometers in the DMSO solution. FT-IR spectrum performed in the Nicolet spectrometers using $\mathrm{KBr}$ pellet. The ${ }^{1} \mathrm{H},{ }^{13} \mathrm{C}$ NMR spectra were recorded in the Bruker $500 \mathrm{MHz}$ in DMSO-d $\mathrm{d}^{6}{ }^{1} \mathrm{H}$ and ${ }^{13} \mathrm{C}$ chemical shift are reported in ppm Vs TMS. Electron spray ionization mass spectrum was measured in the THERMOFINNIGAN LCQ ADVANTAGE MAX mass spectrometer.

\subsubsection{Electrochemicalanalysis}

The electrochemical investigations were carried out using conventional three electrode systems with a saturated calomel electrode as reference and platinum electrode, as counter electrode respectively. The polished high carbon steel (HCS) with an exposed surface area of $1 \mathrm{~cm}^{2}$ in the solution was used as the working electrode. The electrochemical impedance spectroscopy and polarization studies have been performed on the $\mathrm{CH}$ instruments. The EIS measurements were carried out in the frequency range of $1-10000 \mathrm{~Hz}$ with anamplitude of the $10 \mathrm{mV}$ at the open circuit potential. The polarization studies have been performedin the range of 850 to $-150 \mathrm{mV}$ with ascan rate of $1 \mathrm{mV} / \mathrm{S}[7-10]$.

\subsubsection{XPS analysis}

The high carbon steel samples were immersed in the $1 \mathrm{M} \mathrm{HCl}$ solution in the absence and presence of inhibitor for $2 \mathrm{~h}$. X-ray Photoelectron Spectrum was measured on Kratos Axis-Ultra DLD model instrument. The sample was irradiated with $\mathrm{Mg} \mathrm{K \alpha}$ ray source and analyzed with the $1 \mathrm{~cm}^{2}$ surface of the HCS. The electron binding energy was counterbalanced for charging effects by reference to the $\mathrm{C} 1 \mathrm{~s}$ binding energy of surface carbon at $285.0 \mathrm{eV}[11-14]$.

\section{Results and Discussion}

\subsection{Characterization of the inhibitor}

The dithiosemicarbazone derivatives were synthesized and good yields as per the scheme areshown in Fig.1. The UV-Visible spectrum of C1 showing the two characteristic bands at 290 and $300 \mathrm{~nm}$ corresponds to the $\mathrm{n}$ $\pi^{*}$ and $\pi-\pi^{*}$ transitions arising from the thiosemicarbazone moiety. C2 shows two bands at 260 and $280 \mathrm{~nm}$ respectively. IR spectra of the two compounds show N-H stretch at 3441(C1) and 3400(C2), C=N stretching at $1572(\mathrm{C} 1)$ and $1570(\mathrm{C} 2)$, and $\mathrm{C}=\mathrm{S}$ stretching at $1294(\mathrm{C} 1)$ and $1270(\mathrm{C} 2) \mathrm{cm}^{-1}$ respectively. These bands are characteristics of the structure as shown in fig.1.

\subsection{Electrochemical impedance spectroscopy}

Fig 2 showed the Nyquist plots of the HCS in the absence and presence of the inhibitor in the 1M HCl medium. The impedance curves reveal depressed semicircle capacitive loop at the higher frequency, small inductive loop at low frequency [15-17]. The capacitive loop originates from the adsorption on the reaction surface and charges transfer resistance $\left(\mathrm{R}_{\mathrm{ct}}\right)$ [18-21]. The concentration of inhibitor changes from 20-100ppm, the surface layer increases with increasing the diameter of the depressed semi-circle, charge transfer resistance increases and there is a decrease in the dielectric constant as inferred from the tables. In terms of the constant phase element (CPE) expressed as following equation:

$$
\mathrm{Z}_{\mathrm{CPE}}=\mathrm{K}^{-1}(\mathrm{jW})^{-\mathrm{n}}
$$


$\mathrm{K}$ is the CPE constant (in $\left.\Omega^{-1} \mathrm{~s}^{\mathrm{n}} \mathrm{cm}^{-2}\right), \mathrm{j}=\sqrt{ }-1, \omega$ is the angular frequency in rad $\mathrm{s}-1(\omega=2 \pi f, \mathrm{f}$ is the angular frequency in $\mathrm{Hz}$ ).

Figure 1: synthesis scheme and Structure of the C1-C2

Fig.2 and table 1, 2, data clearly indicating that $\mathrm{R}_{\mathrm{ct}}$ values are increased and the capacitance $\left(\mathrm{C}_{\mathrm{dl}}\right)$ values decrease while increasing the concentration of the inhibitor [22-25]. The surface layer increase with the increasing concentration of the inhibitor and the percentage inhibition efficiency reached the maximum for the inhibitor up to $95.3(\mathrm{C} 1)$ and $96.1(\mathrm{C} 2)$ at the 100ppm concentration. The compound (C2) act as a better inhibition efficiency compared to $(\mathrm{C} 1)$. The data fit with a circuit consisting of the constant single-phase element charges-metal surface and solution [26-27].
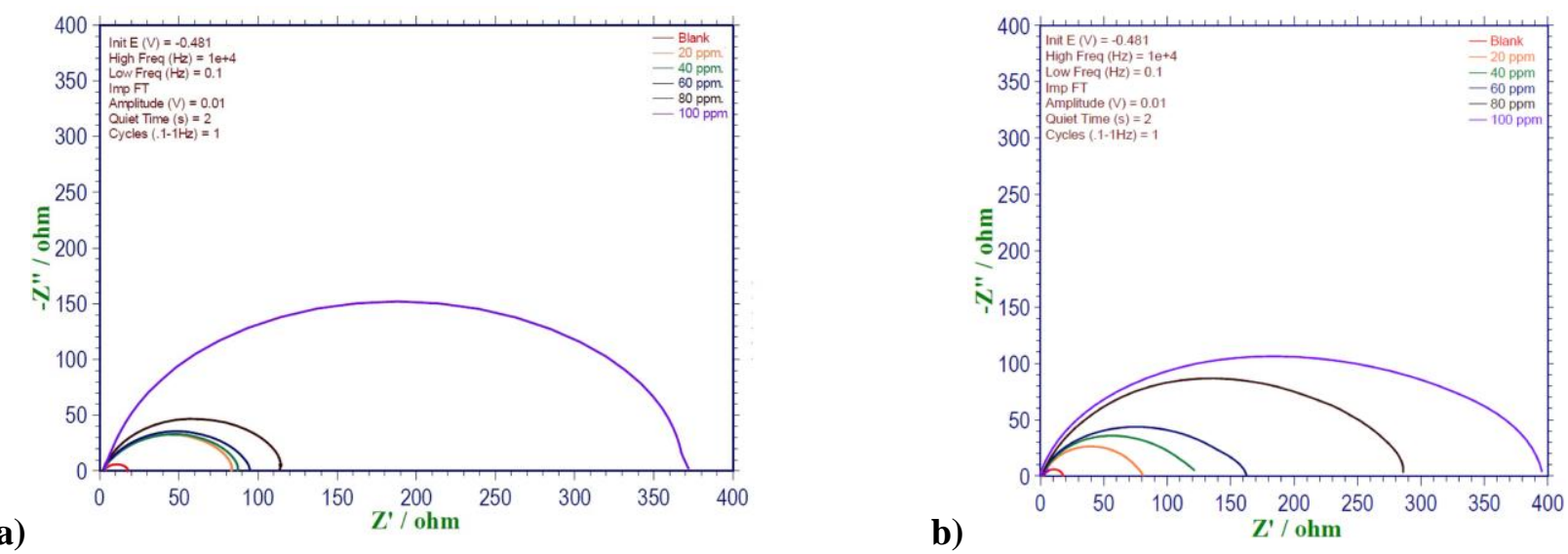

Figure 2: Electrochemical impedance spectra of $\mathrm{HCS}$ in $1 \mathrm{M} \mathrm{HCl}$ in absence and presence of a) $\mathrm{Cl}$ b) $\mathrm{C} 2$

Table 1: EIS for HCS immersed in 1.0 M HCl solution in presence of various concentrations of $\mathrm{C} 1$.

\begin{tabular}{ccccc}
\hline $\begin{array}{c}\text { Inhibitor } \\
\text { concentration }(\mathrm{ppm})\end{array}$ & $\begin{array}{c}\mathrm{R}_{\mathrm{ct}} \\
\left(\Omega \mathrm{Cm}^{2}\right)\end{array}$ & $\begin{array}{c}\mathrm{C}_{\mathrm{dl}} \\
(\mu \mathrm{F} \mathrm{Cm})\end{array}$ & $\mathrm{IE} \mathrm{( \% )}$ & $\theta$ \\
\hline Blank & 15.15 & 289.08 & & \\
20 & 81.2 & 97.22 & 77.8 & 0.778 \\
40 & 120.0 & 41.87 & 85.8 & 0.850 \\
60 & 162.2 & 37.55 & 88.9 & 0.889 \\
80 & 292.0 & 30.63 & 93.8 & 0.938 \\
100 & 395.0 & 10.33 & 95.4 & 0.954 \\
\hline
\end{tabular}



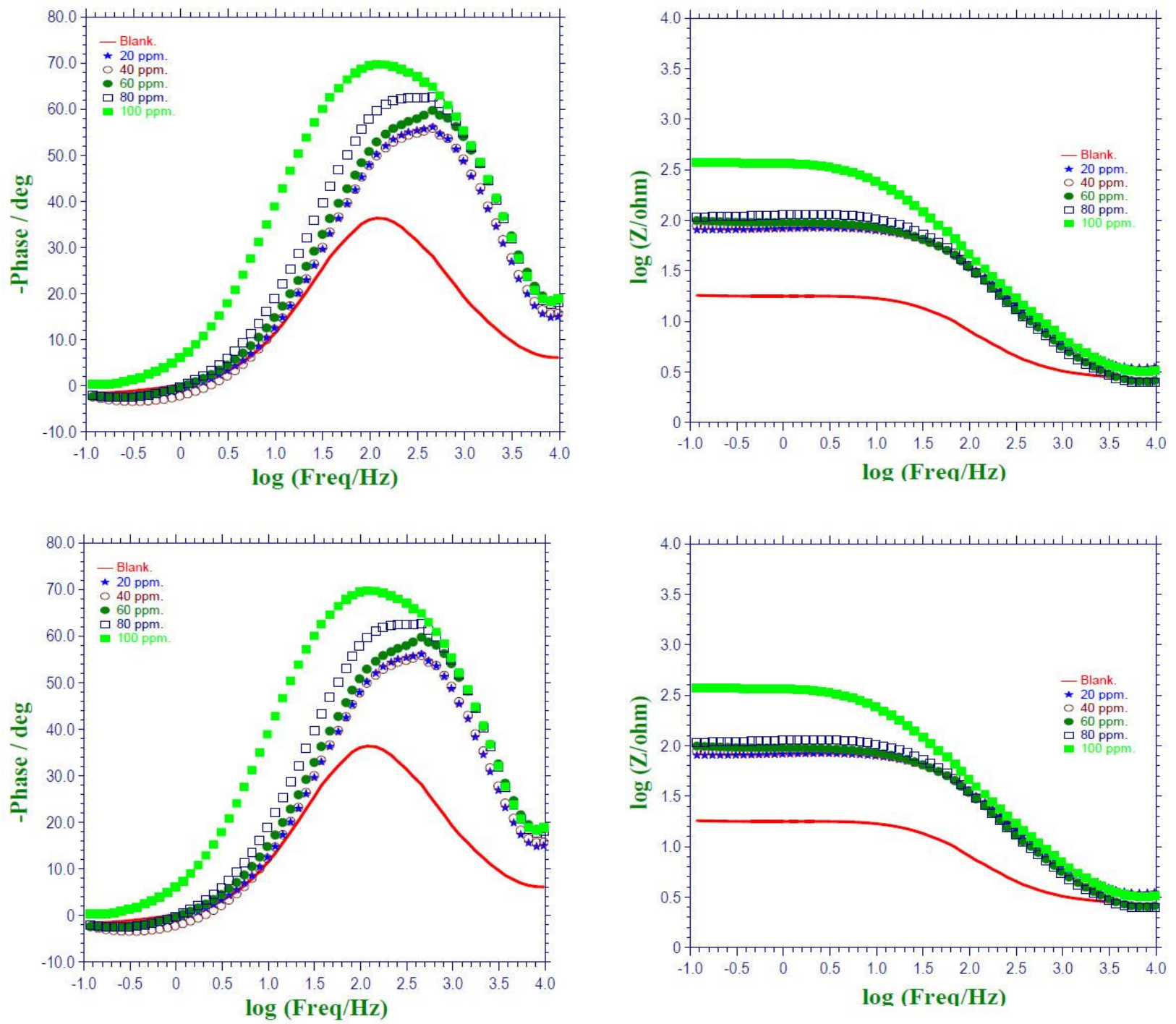

Figure 3: Electrochemical impedance spectra of $\mathrm{HCS}$ in $1 \mathrm{M} \mathrm{HCl}$ in the absence and presence of a) $\mathrm{C} 1 \mathrm{~b}$ ) $\mathrm{C} 2$ Bode plot.

Table 2: EIS for HCS immersed in 1.0 M HCl solution in presence of various concentrations of C2.

\begin{tabular}{ccccc}
\hline $\begin{array}{c}\text { Inhibitor } \\
\text { concentration }(\mathrm{ppm})\end{array}$ & $\begin{array}{c}\mathrm{R}_{\mathrm{ct}} \\
\left(\Omega \mathrm{Cm}^{2}\right)\end{array}$ & $\begin{array}{c}\mathrm{C}_{\mathrm{dl}} \\
\left(\mu \mathrm{F} \mathrm{Cm}^{2}\right)\end{array}$ & IE (\%) & $\theta$ \\
\hline Blank & 15.15 & 289.08 & & \\
20 & 81.5 & 35.85 & 80.9 & 0.809 \\
40 & 121.7 & 23.13 & 87.2 & 0.872 \\
60 & 162.9 & 15.92 & 90.5 & 0.905 \\
80 & 286.2 & 8.74 & 94.6 & 0.946 \\
100 & 395.5 & 4.17 & 96.1 & 0.961 \\
\hline
\end{tabular}

\subsection{Tafel polarization measurements}

The results of the Tafel polarization measurements are shown in Fig 4. The electrochemical parameters such as corrosion potential $\left(\mathrm{E}_{\text {corr }}\right)$, corrosion current density $\left(\mathrm{I}_{\mathrm{corr}}\right)$, anodic Tafel slope $\left(\mathrm{b}_{\mathrm{a}}\right)$ and cathodic Tafel slope $\left(\mathrm{b}_{\mathrm{c}}\right)$ were extrapolated from the curves are given in Table 3 for both the inhibitors. As seen from the Fig. 4. The adsorption of the inhibitor on the surface of the high carbon steel reduces the anodic dissolution of iron and delays cathodic hydrogen evolution reactions [28-32]. The corrosion potential does not shift remarkably while changing the inhibitor concentration. It clearly indicates that inhibitor acted as a mixed type of inhibitor in acid medium and $\mathrm{C} 2$ has better inhibitor efficiency than $\mathrm{C} 1$ 

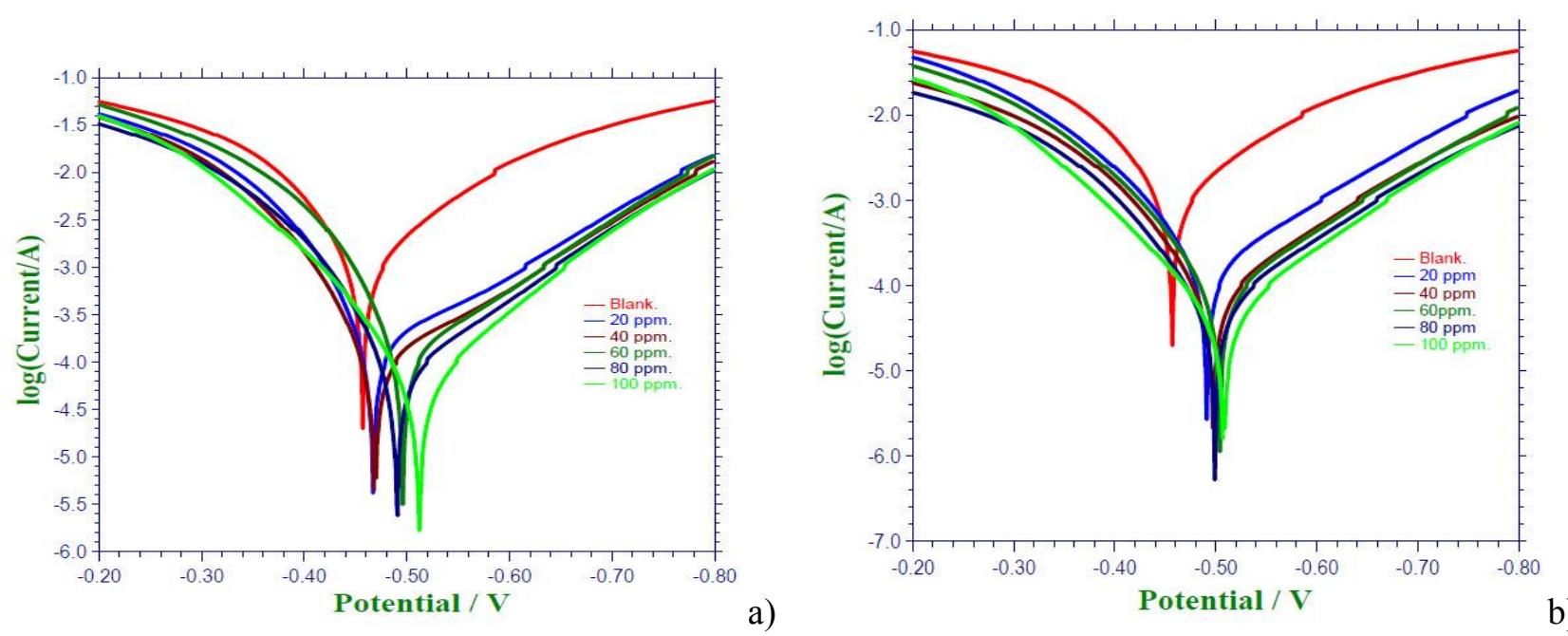

Figure 4:Tafel plotsof $\mathrm{HCS}$ in $1 \mathrm{M} \mathrm{HCl}$ in the absence and presence of a) $\mathrm{C} 1 \mathrm{~b}$ ) $\mathrm{C} 2$

Table 3: Tafel for HCS immersed in $1.0 \mathrm{M} \mathrm{HCl}$ solution in presence of various concentrations of $\mathrm{C} 1$.

\begin{tabular}{ccccccc}
\hline $\begin{array}{c}\text { Inhibitor } \\
\text { concentration }(\mathrm{ppm})\end{array}$ & $\begin{array}{c}\mathrm{I}_{\text {corr }} \\
\left(\mu \mathrm{A} \mathrm{cm}^{-2}\right)\end{array}$ & $\begin{array}{c}\mathrm{E}_{\text {corr }} \\
(\mathrm{V} / \mathrm{SCE})\end{array}$ & $\begin{array}{c}\beta_{\mathrm{c}} \\
\left(\mathrm{mV} / \mathrm{dec}^{1}\right)\end{array}$ & $\begin{array}{c}\beta_{\mathrm{a}} \\
\left(\mathrm{mV} / \mathrm{dec}^{1}\right)\end{array}$ & $\mathrm{IE} \mathrm{( \% )}$ & $\theta$ \\
\hline Blank & 15.01 & & 7.304 & 8.471 & & \\
20 & 2.64 & 0.4720 & 6.23 & 7.105 & 82.42 & 0.82 \\
40 & 1.94 & 0.4655 & 7.424 & 11.899 & 87.09 & 0.87 \\
60 & 1.67 & 0.4733 & 5.589 & 9.531 & 88.94 & 0.89 \\
80 & 1.15 & 0.4930 & 6.352 & 7.842 & 92.42 & 0.92 \\
100 & 0.84 & 0.4890 & 6.230 & 7.105 & 94.40 & 0.94 \\
\hline
\end{tabular}

Table 4: Tafel for $\mathrm{HCS}$ in 1.0 $\mathrm{M} \mathrm{HCl}$ solution in presence of various concentrations of $\mathrm{C} 2$.

\begin{tabular}{ccccccc}
\hline $\begin{array}{c}\text { Inhibitor } \\
\text { concentration }(\mathrm{ppm})\end{array}$ & $\begin{array}{c}\mathrm{I}_{\text {corr }} \\
(\mu \mathrm{A} \mathrm{cm})^{-2}\end{array}$ & $\begin{array}{c}\mathrm{E}_{\text {corr }} \\
(\mathrm{V} / \mathrm{SCE})\end{array}$ & $\begin{array}{c}\beta_{\mathrm{c}} \\
\left(\mathrm{mV} / \mathrm{dec}^{1}\right)\end{array}$ & $\begin{array}{c}\beta_{\mathrm{a}} \\
\left(\mathrm{mV} / \mathrm{dec}^{1}\right)\end{array}$ & IE (\%) & $\theta$ \\
\hline Blank & 15.01 & & 7.304 & 8.471 & & \\
20 & 1.72 & 0.4936 & 7.404 & 13.888 & 88.54 & 0.88 \\
40 & 0.95 & 0.4969 & 6.734 & 11.770 & 93.67 & 0.93 \\
60 & 0.87 & 0.5036 & 7.632 & 13.681 & 94.20 & 0.94 \\
80 & 0.59 & 0.4956 & 7.643 & 12.654 & 96.10 & 0.96 \\
100 & 0.48 & 0.5058 & 8.067 & 10.829 & 96.80 & 0.97 \\
\hline
\end{tabular}

\subsection{XPS spectrum of the C2}

The XPS Spectrum measurement was carried out with the mechanically polished specimens of the high carbon steel in acid absence and presence of the inhibitor. The XPS core level spectra provide the valuable information about the chemical composition of inhibitor and the result shows in the (Fig 5). The $\mathrm{C}_{1 \mathrm{~s}}$ spectrum of the inhibitor has been shown in Fig 5. The $\mathrm{C}_{1 \mathrm{~s}}$ spectrum has the two kinds of the binding energy peaks at the 285.0 $\mathrm{eV}$ and $286.0 \mathrm{eV}$ the first peak at $285.0 \mathrm{eV}$ corresponds to the $-\mathrm{C}-\mathrm{C}-$ or $\mathrm{CH}_{\mathrm{n}}$ binding energy peaks [33-34]. The second peak at $286.0 \mathrm{eV}$ corresponds to the $\mathrm{C}-\mathrm{N}$ of the inhibitor [37]. The $\mathrm{N}_{1 \mathrm{~s}}$ spectrum has contained the number of overlapping spectrum, it has the peak at $400.0 \mathrm{eV}$ corresponds to the $\mathrm{C}-\mathrm{N}$ species, $401.0 \mathrm{eV}$ related to the $\mathrm{Fe}-\mathrm{N}$ species which nitrogen atom of the inhibitor interaction with the $\mathrm{Fe}$ atom in the high carbon steel [3538]. The $\mathrm{O}_{1 \mathrm{~s}}$ spectrum of the as shown in Fig 6., it comprises the overlapping of the number spectrum. Binding energy peak at $530.0 \mathrm{eV}$ related to the $\mathrm{OH}$ species, the second peak at $531.2 \mathrm{eV}$ related to the $\mathrm{O}^{2-}$ species [3640]. The $S_{2 p}$ spectrum seen in Fig 6., it shows a single peak with several overlapping spectrums. The $S_{2 p}$ has the signal at the $162.0 \mathrm{eV}$ due to the $\mathrm{FeS}$, second signal at $164.0 \mathrm{eV}$ due to the $\mathrm{FeS}_{\mathrm{n}}$. The $\mathrm{Fe}_{2 \mathrm{p}}$ spectrum have the three peaks, peak $711.0 \mathrm{eV}$ correspond to the $\mathrm{Fe}^{3 / 2}$ state, peak at $725.0 \mathrm{eV}$ corresponds to the $\mathrm{Fe}^{1 / 2}$, the third peak at $719.0 \mathrm{eV}$ corresponds to the satellite peak of the inter system crossing of the $\mathrm{Fe}^{3 / 2}$ and $\mathrm{Fe}^{1 / 2}$ of the iron in the high carbon steel, in the case of the absence of the inhibitor on the high carbon steel there is no satellite peak it also further confirm that inhibitor has adsorbed on the surface of the high carbon steel and form the protective layer at the 100ppm concentration of the inhibitor[40-43]. The XPS results of the element of the $\mathrm{C}_{1 \mathrm{~s}}, \mathrm{~N}_{1 \mathrm{~s}}, \mathrm{O}_{1 \mathrm{~s}}$, 
$\mathrm{S}_{2 \mathrm{p}}$ and $\mathrm{Fe}_{2 \mathrm{p}}$ reveals that inhibitor absorbed on the HCS surface and form the protecting layer which diminishes the corrosion.
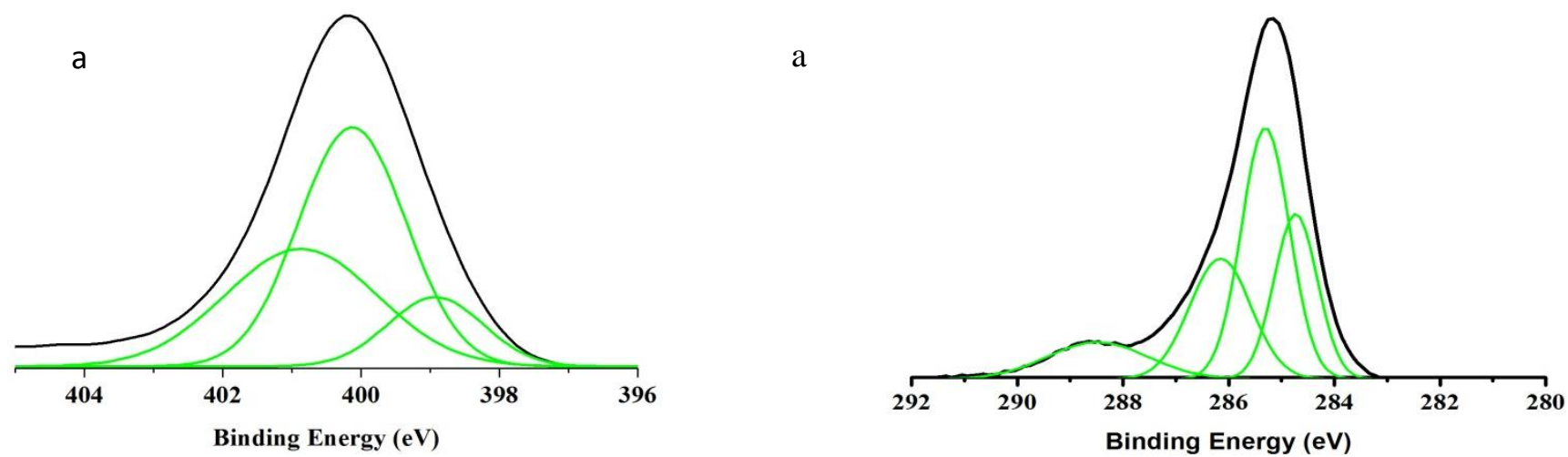

Figure 5: HCS spectra of a) N1s, b) C1s, in presence of 100ppm concentrations of C1
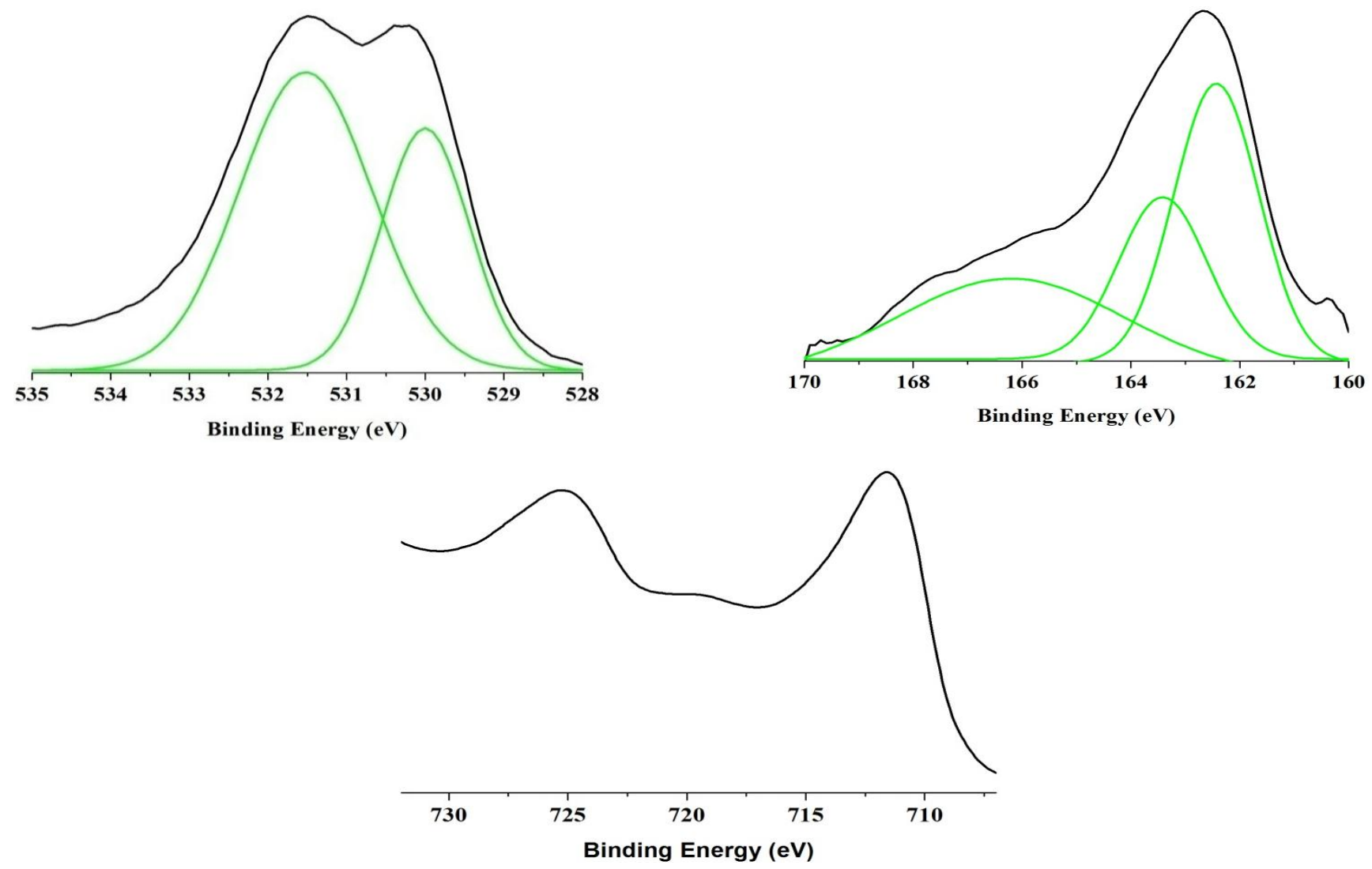

Figure 6: HCS spectra of a) O2s, b) S2p c) Fe2p, in presence of 100ppm concentrations of inhibitor C1

\subsection{UV-Visible and IR spectroscopy}

UV-Visible spectra were recorded on the samples after the experiments were done and the surface was scrapped and dissolved in DMSO. The spectra show a new band at $580 \mathrm{~nm}$ in additions to those bands which are discussed earlier. The original peaks of the inhibitors undergo a hypsochromic shift because of surface coordination. The band at $580 \mathrm{~nm}$ is typical of d-d transitions observed in the Fe (III) complexes. It clearly indicates the formation of chemisorbed films of the inhibitor on the HCS surface. The FTIR spectra of the scraped samples of the both high carbon steel show the shifting on their stretching frequency of the inhibitor reveal that the inhibitor coordinate to the surface of the metal active site. The broad band at 3100-3400 assigned to the stretching frequency of the water, $\mathrm{NH}$ stretching band disappears of $\mathrm{C}=\mathrm{N}$ at $1618(\mathrm{C} 1)$ and $1628(\mathrm{C} 2), \mathrm{C}$ S stretching band at $1378(\mathrm{C} 1)$ and 1383 (C2) due to the Metal and (C1\&C2) complex. The shifting of IR value clearly indicates those inhibitors was absorbed on the metal surface and protect the corrosion from the acid. 
Table 5: XPS for the metal absence and presence of C2

\begin{tabular}{|c|c|c|c|c|}
\hline \multirow[b]{2}{*}{ Substrate } & \multicolumn{2}{|c|}{ High Carbon steel } & \multicolumn{2}{|c|}{ HCS with inhibitor } \\
\hline & $\mathrm{BE} / \mathrm{eV}$ & Assignment & $\mathrm{BE} / \mathrm{eV}$ & Assignment \\
\hline \multirow{5}{*}{$\mathrm{C} 1 \mathrm{~s}$} & \multirow{5}{*}{285.1} & \multirow{4}{*}{$-\mathrm{C}-$, } & 284.75 & $-\mathrm{C}-$ \\
\hline & & & 285.35 & \\
\hline & & & 286.15 & $-\mathrm{CH}_{3}$ \\
\hline & & & 288.45 & $\mathrm{C}-\mathrm{N}$ \\
\hline & & & 398.95 & $\mathrm{C}-\mathrm{N}$ \\
\hline \multirow[t]{2}{*}{ N1s } & & & 400.15 & $\mathrm{~N}-\mathrm{N}$ \\
\hline & & & 400.85 & $\mathrm{~N}=\mathrm{N}$ \\
\hline \multirow[t]{2}{*}{$\mathrm{O} 2 \mathrm{~s}$} & & & 530.0 & $\mathrm{FeO}$ \\
\hline & & & 531.6 & $\mathrm{FeOOH}$ \\
\hline \multirow[t]{3}{*}{ S2p } & & & 162.4 & $\mathrm{Fe}_{1-x} \mathrm{~S}$ \\
\hline & & & 163.4 & $-S-$ \\
\hline & & & 166.2 & $\mathrm{~S}_{6}$ \\
\hline \multirow[t]{3}{*}{$\mathrm{Fe} 2 \mathrm{p}$} & 710.4 & $\mathrm{FeO}$ & 711.65 & $\mathrm{FeO}, \mathrm{FeS}$ \\
\hline & & & 719.95 & \\
\hline & 724.5 & $\mathrm{FeOOH} \mathrm{Fe}{ }_{2} \mathrm{O}_{3}, \mathrm{Fe}_{3} \mathrm{O}_{4}$ & 725.65 & $\mathrm{FeOOH}, \mathrm{Fe}_{2} \mathrm{O}_{3}, \mathrm{Fe}_{3} \mathrm{O}_{4}$ \\
\hline
\end{tabular}

\subsection{Adsorption isotherm}

From the spectral data,there is a definitive chemisorption on the surface to protect against the corrosion of high carbon steel by adsorption on the metal-solution interface. C1\&C2 has adsorbed on the active corrosion site of the metal and diminish the corrosion from the acid. The reactive functional groups present in the $\mathrm{C} 1 \& \mathrm{C} 2$ leads to the chemisorption process. The surface coverage $(\theta)$ for different concentrations of $(\mathrm{C} 1$ and $\mathrm{C} 2)$ in acidic media has been evaluated from impedance measurements and Tafel by using the following equation [44]:

Fig.7 (a, b) Shows the plot of $\mathrm{C}_{\mathrm{inh}} / \theta$ vs. $\mathrm{C}_{\mathrm{inh}}$ yielded the straight line. The linear correlation coefficient $\left(\mathrm{r}^{2}\right)$ is almost equal to $1\left(r^{2}=0.99\right)$ and the slope is very close to 1 , indicating the adsorption of synthesized $(\mathrm{C} 1 \& \mathrm{C} 2)$ on the metal surface obeys the Langmuir adsorption isotherm. The equilibrium constant $\left(\mathrm{K}_{\mathrm{ads}}\right)$ for the adsorption of $(\mathrm{C} 1 \& \mathrm{C} 2)$ was calculated from the reciprocal of the intercept straight line. The free energy of the absorption was calculated from the following equation:

$$
\Delta \mathrm{G}_{\mathrm{ads}}=-\mathrm{RT} \ln \mathrm{K}_{\mathrm{ads}}
$$

Calculated free energy and equilibrium constant is given in Table 5. The spontaneity and stability of the adsorption on the HCS surface of inhibitor occurred from the negative value of the free energy. The free energy values indicate a strong adsorption of the synthesized $(\mathrm{C} 1 \& \mathrm{C} 2)$ on the surface of carbon steel in $1.0 \mathrm{M} \mathrm{HCl}$. According to Noor [45], $\Delta \mathrm{G}_{\text {ads }}$ values in between -20 to $-40 \mathrm{~kJ} \mathrm{~mol}^{-1}$ mixed type of inhibitors (chemisorption and physisorption). For our investigation $\mathrm{C} 1 \Delta \mathrm{G}_{\mathrm{ads}}$ value -33.81(EIS) and -34.79 (Tafel), $\mathrm{C} 2 \Delta \mathrm{G}_{\text {ads }}$ value -34.30 (EIS) and -36.41 (Tafel). $\Delta \mathrm{G}_{\mathrm{ads}}$ values indicate that the $(\mathrm{C} 1 \& \mathrm{C} 2)$ were mixed type inhibitor both chemisorption (electrostatic) and physisorption (charge transfer) and their value were in between -20 to $-40 \mathrm{~kJ} \mathrm{~mol}^{-1}$.

Table 8: Langmuir adsorption isotherm for HCS immersed in $1.0 \mathrm{M} \mathrm{HCl}$ solution in presence of C1-C2

\begin{tabular}{cccccc}
\hline Metal & Methods & $\mathrm{R}^{2}$ & Slope & $\Delta \mathrm{G}_{\text {ads }}(\mathrm{kJ} / \mathrm{mol})$ & $\mathrm{K}_{\text {ads }}(\mathrm{kJ} / \mathrm{mol})$ \\
\hline $\mathrm{C} 1$ & EIS & 0.9986 & 1.0100 & -33.81 & 13897 \\
& Tafel & 0.9987 & 1.0196 & -34.79 & 20593 \\
$\mathrm{C} 2$ & EIS & 0.9990 & 1.0142 & -34.30 & 16915 \\
& Tafel & 0.9998 & 1.0009 & -36.41 & 39525 \\
\hline
\end{tabular}



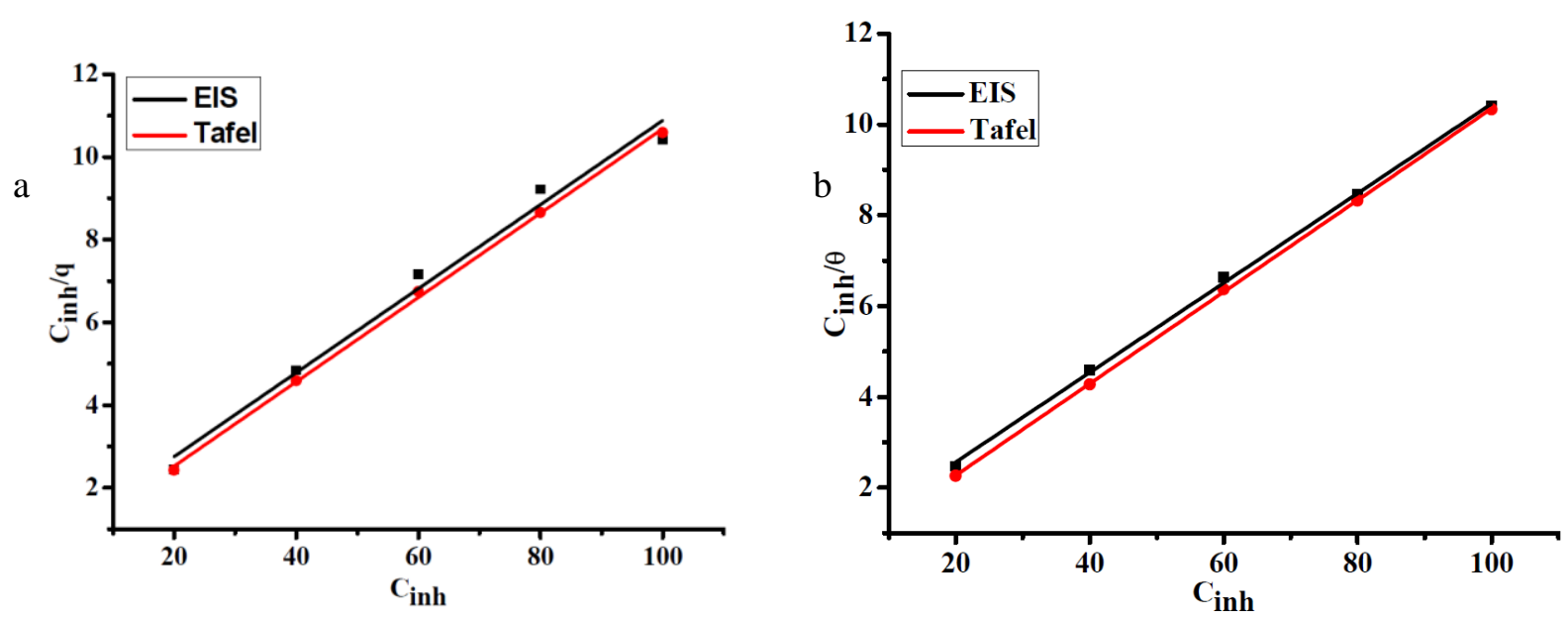

Fig.7 (a, b) : Plots of $\mathrm{C}_{\text {inh }} / \theta$ vs. $\mathrm{C}_{\text {inh }}$

\subsection{Mechanism of inhibition}

The inhibitors, EIS results clearly indicating the increased $R_{c t}$ and decreased $C_{d r}$ respectively,suggested that inhibitor species function by adsorption at the metal/solution interface.the adsorption may be possible in three ways first one, charge transfer interaction of lone pair of electron in N,S or $\pi$ electrons of the aromatic ring with vacant $\mathrm{d}$ orbitals of the $\mathrm{Fe}$ (chemisorption at anodic site), second electrostatic interaction between aromatic ring with $\mathrm{Fe}$ surface (physisorption at cathodic site ), third was combination of both. According to Noor [45], $\Delta \mathrm{G}_{\mathrm{ads}}$ value was less than-20kJ mol ${ }^{-1}$ it leads to physisorption,more than $-40 \mathrm{~kJ} \mathrm{~mol}^{-1}$ chemisorption. In our study $\Delta \mathrm{G}_{\text {ads }}$ value of the $\mathrm{C} 1, \mathrm{C} 2$ were around -34 to $-36 \mathrm{~kJ} \mathrm{~mol}^{-1} . \Delta \mathrm{G}_{\mathrm{ads}}$ value suggested that adsorption of piperazine dithiosemicarbazone on the high carbon steel surface arisen by both charge transfer $(\mathrm{C}=\mathrm{S},-\mathrm{NH})$ and electrostatic interaction ( $\pi$ electrons of the aromatic ring) Bis (Benzoyl pyridine) piperazine dithiosemicarbazone has been better inhibitive properties due to course of extra aromatic ring compared with Bis (pyridine-2-carboxaldehyde) piperazine dithiosemicarbazone.

\section{Conclusions}

Bis (Benzoyl pyridine) piperazine dithiosemicarbazone (C2) have been good inhibition efficiency compared to Bis (pyridine-2-carboxaldehyde) piperazine dithiosemicarbazone (C1), on the corrosion of mild steel in $1 \mathrm{M} \mathrm{HCl}$ medium. Electrochemical studies EIS and polarization result reveals that the inhibition efficiency of the inhibitor increases with increasing concentration in high carbon steel. XPS surface analysis shows characterize passive film formed on the mild steel upon immersion in the acid. The adsorption of $\mathrm{C} 1$ and $\mathrm{C} 2 \mathrm{in} 1 \mathrm{M} \mathrm{HCl}$ on the surface of high carbon steel obeys the Langmuir adsorption isotherm.

\section{References}

1. H. Lgaz, R. Salghi, S. Jodeh, B. Hammouti, J. Mol. Liq. 225 (2017) 271-280.

2. C. Kustu, C. Kaan, Emregul, O. Atakol, Corros. Sci. 49 (2007) 2800-2811.

3. A. Doner, R. Solmaz, M. Ozcan, G. Kardas, Corros. Sci. 53 (2011) 2902-2913.

4. A. Samide, B. Tutunaru, C. Negrila, Chem. Biochem. Eng. Q. 25 (2011) 299-308.

5. J.K. Swearingen, D. X. West, Transition Metal Chemistry. 25 (2000) 241-246.

6. R. Chandra, O. P. Pandey, S. K. Sengupta, J. Agric. Food Chem.53 (2005) 2181-2184.

7. R. Tamilarasan, A. Sreekanth, RSC Adv. 3 (2013) 23681-23691.

8. E.E. Oguzie, Mater Lett. 59 (2005)1076-1079.

9. M.A. Quraishi, I.Ahmad, A.K. Singh, Mater Chem Phys.112 (2008) 1035-1042.

10. N.A. Negm, M.F. Zaki, J. Surf Deterg. 12 (2009) 321-329.

11. K.S. Jacob, G. Parameswaran, Corros. Sci. 52 (2010) 224-228.

12. R. Solmaz, Corros. Sci. 52 (2010) 3321-3330.

13. S. Xianghong, S.Deng, H. Fu, Corros. Sci. 53 (2011) 1529-15.

14. S. Safak, B. Duran, A. Yurt, G. Turkoglu, Corros. Sci. 54 (2012) 251-259.

15. B.V. Crist, XPS Reports. 1 (2007) 1-52.

16. A.A. Refaie, J. Walton, R.A. Cottis, R. Lindsay, Corros. Sci. 52 (2010) 422-428.

17. G. Gece, Corros. Sci. 50 (2008) 2981-2992. 
18. S. DemetOzkır, K. Kayakırılmaz, E. Bayol, A.A. Gurten, F. Kandemirli, Corros. Sci. 56 (2010) 143152.

19. H.A. Sorkhabi, N.G. Jeddi, F. Hashemzadeh, H. Jahani, Electrochimica Acta. 50 (2006) 3848-3854.

20. L. Elkadi, B. Mernari, M. Traisnel, F. Bentiss, M. Lagrenee, Corros. Sci. 42 (2000) 703-710.

21. M.A. Hegazy, A.M. Badawi, S.S. Abd El Rehim, W.M. Kamel, Corros. Sci. 56 (2012) 143-88.

22. S.S. Rahim, H.H. Hassan, M. A. Amin, Mater. Chem. Phys. 70 (2001) 64-72.

23. A. Yurt, S. Ulutas, H. Dal, Appl. Surf. Sci. 253 (2006) 919-925.

24. M.J. RodiguezPresa, R.I. Tucceri, M.I. Florit, D. Posadas, J. Electroanal. Chem. 475 (1999) 152.

25. B.D. Mert, M.E. Mert, G. Kardas, B. Yaz, Corros. Sci. 53 (2011) 4265-4272.

26. M. Abdallah, I. Zaafarany, S.O. Al-Karanee, A.A. Abd El-Fattah, Arabian Journal of Chemistry, 5 (2012) 225-234

27. M.S. Morad, Corros. Sci. 42 (2000) 1307-1315.

28. Aljourani, J. Raeissi, K. Golozar, Corros. Sci. 51 (2009) 1836-1843.

29. S. H. AshassiSorkhabi, B. Shabani, B. Aligholipour, D. Seifzadeh, Appl. Surf. Sci. 252 (2006) 40394047.

30. M. O. Watanabe, S. Itoh, K. Mizushima, T. Sasaki, Appl. Phys. Lett. 68 (1986) 2962-2964.

31. P. Galicia, N. Batina, I. Gonzalez, J. Phys. Chem. B 110 (2006) 14398-14405.

32. S. Feliu Jr, V. Barranco, Acta Materialia 51 (2003) 5413-5424.

33. F. Bentiss, M. Traisnel, L. Gengembre, M. Lagrene, Appl. Surf. Sci. 152 (1999) 237-24.

34. V. S. Sastri, M. Elboujdaini, J. R. Brown, Corros. Sci. 52 (1996) 447-452.

35. T. Reier, S. Simson, J. W. Schultze, Electrochimica Acta 43 (1998) 149-148.

36. S. N.S. McIntyre, D.C. Zetaruk, Anal. Chem. 49 (1977) 1521.

37. C.R. Brundle, T.J. Chuang, K. Wandelt, Surf. Sci. 68 (1977) 459.

38. H. Abdel-Samad, P. R. Watson, Appl. Surf. Sci. 136 (1998) 46-54.

39. L. Forget, F. Wilwers, J. Delhalle, Z. Mekhalif, Appl. Surf. Sci. 205 (2003) 44-45.

40. D.D. Hawn, B.M. DeKoven, Surf. Interface Anal. 10 (1987) 63.

41. M. Muhler, R. Schlogl, G. Ertl, J. Catal. 138 (1992) 413.

42. C.D. Wagner, L.H. Gale, R.H. Raymond, Anal. Chem. 51 (1979) 466.

43. T. Yamashita, P. Hayes, Appl. Surf. Sci. 254 (2008) 2441-2449.

44. P. Velasquez, J.R. Barrado, R. Cordova, Surf. Interface Anal. 30 (2000) 149-153.

45. E.A. Noor, Int. J. Electrochem. Sci.2 (2007) 996.

46. M. El Faydy, T. Djassinra, S. Haida, M. Rbaa, K. Ounine, A. Kribii, B. Lakhrissi, J. Mater. Environ. Sci. 8 (2017) 3855-3863.

47. L. El Ouasif, I,Merini, H. Zarrok, M. El ghoul, R. Achour, A. Guenbour, H. Oudda, F. El-Hajjaji, B. Hammouti, J. Mater. Environ. Sci. 7 (8) (2016) 2718-2730.

\section{(2018) ; http://www.jmaterenvironsci.com}

